Cogliolo, Pietro - Filosofia do Direito Privado, trad. portuguesa de Eduardo Espinola, apud Eduardo Espinola - A Família no Direito Brasileiro, Ed. Gazeta Judiciária, Rio, 1954.

Correia, Alexandre e Sciascia, Gaetano - Manual de Direito Romano, Edição Série Cadernos Didáticos. Livros Cadernos Ltda., Rio de Janeiro.

Cunha Gonçalves, Luiz da - Tratado de Direito Civil, Vol. I, tomo I, Ed. Max Limonad, São Paulo, 1955. De Cicco, Cláudio - Direito: Tradigáa e Modernidade, Icone Editora, São Paulo, 1993.

Diniz, Maria Helena - Curso de Direito Civil Brasileiro, Vol. 5², Edição Saraiva, São Paulo, 1985

Echeverria, Lamberto - Código de Derecho Canónico, Edicáo Bilingüe Comentada, Ed. Biblioteca de Autores Cristianos (BAC), Madrid, 1985.

Émile Benveniste - Le Vocubulaire des Institutions Indo Europínar Vol I Economie, Parenté, Societe, Édiions de Minuit, Paris, 1969, apud Cláudio de Cicco Direito: Tradisão e Modernidade, cit., págs. 22-23.

Espinola, Eduardo - A Família no Direito Brasileiro, Ed. Gazeta Judiciária, Rio de Janeiro, 1954

Fustel de Coulanges, Numa Dénis - La Cité Antique, pág. 93, Édition Hachette, Paris, 1881, apud Cláudio de Cicco - Direito: Tradisáa e Modernidade, cit., pág. 22.

Galvão de Souza, José Pedro - Direito Natural, Direito Positivo, Estado de Direito, Edição RT, São Paulo, 1977

Garcia y Garcia, Antonio - Historia del Derecbo Canón co, Edição Instituto de Historia de la Theologia Española, Salamancha, 1967.

João Paulo II - Carta Encíclica Centesimus Annus, trad. portuguesa, Ediçōes Paulinas, São Paulo, 1991.

Kipp, Theodor y Wolff, Martin - Tratado de Derecho civil - Derecho de Familia, trad. esp., Vol. IV, Editoria Bosch, Barcelona, 1979

Lalande, André - Vocabulaire Tecnique el Critique de Pbilosophis 17e Édition, Presses Universit France, Paris, 1991 ehmann, Heinrich - Derectoo de Família, trad. espanhola, Editorial Revista de Derecho Privado, Madrid, 1953. Lombardia, Pedro - Lezioni di Diritto Canonico, Part Generale, Giuffrè Editore, Milano, 1985.

Nielsen Neto, Henrique - Filosofia básica Atual Editora Ltda., São Paulo, 1991.

Nogueira, Paulo Lúcio - Estatuto da Criansa e do Adoles. cente Comentado, Edição Saraiva, São Paulo, 1991. Petit, Eugêne - Tratado Elemental de Derecho Romano, Editorial Albatroz, Buenos Aires, 1970.

Pinto Ferreira, Luiz - Dicionário de Sociologia, Ed. José Bushatsky Editor, São Paulo, 1977.

Pontes de Miranda - Tratado de Direito Privado, tomo VII, Edição Konfino, Rio de Janeiro, 1971

uglia, Ferdinando - Saggi di Filosofia Giuridica, Ed. Ernesto Anfossi, Napoli, 1885

Reale, Miguel - Filosofic em São Paulo, Editora Grijalbo, São Paulo, 1976.

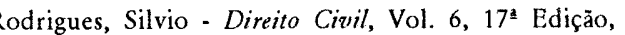
Saraiva, São Paulo, 1991

Savatier, René - Les Métamorphoses Économiques et Socials du Droit Civil d'Aujourd'bui, 2e. Édition, Paris, 1952 apud Silvio Rodrigues - Direito Cinil, cit., págs. 6-7 nota no 2 .

Scherillo, Gaetano - Corso di Istituzioni di Diritto Roma$n o$, vol. I, Ed. La Goliardica, Milano.

Sciascia, Gaetano e Correia, Alexandre - Manual Direro Remano Ediço Séri Cadernos Didricos Livros Cadernos Ltda., Rio de Janeiro.

Viana, Marco Aurélio S. - Curso de Direito Cinil, Del Rey Editora, Belo Horizonte, 1993.

itale, Antonio - Corso di Diritto Eclesiastico, Giuffr Editore, Milano, 1989.

Wald, Arnoldo - Curso de Direito Civil Brasileiro - Direito de Família, Vol. IV, Edição RT, São Paulo, 1990.

Wolff, Martin

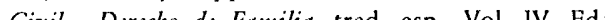
Bosch, Barcelona, 1979.

\section{Efetividade e processo cautelar}

Comunicação apresentada ao II Congresso Brasileiro de Direito Processual, Porto Alegre, agosto/1993

Carlos Alberto Alvaro de Oliveira

Professor da Faculdade de Direito da UFRGS

1. A distância entre a mera proclamação e a tutela efetiva do direito, com meios eficazes e expeditos, constitui um dos problemas cruciais do processo civil de nossa época. Não é suficiente que a Constituição apregoe a República Federativa do Brasil como um Estado Democrático de Direito (art.1 ${ }^{\circ}$, caput), ou assegure a inviolabilidade do direito à vida, à liberdade, à segurança à propriedade (art. $5^{\circ}$, caput). Tampouco satisfaz a simples garantia, no plano do verbo, de acesso ao Poder Judiciário para a apreciação de qualquer lesão on ameasa direito (art. 5o, XXXV). Tudo isso será ilusó rio se o usuário da Justiça não puder obter a satisfação de sua pretensão com um custo razoável, proporcional às suas posses e ao objeto do litígio, e em tempo adequado para que a demora não transforme a justiça em injustiça.

O problema se agudiza especialmente em termos brasileiros, face à crônica desproporção entre o número de magistrados e a quantidade de causas, a que vem se somar a proverbial escassez dos recursos destinados à administração da justiça. A questão dos meios mostra-se particularmente grave por dificultar o recrutamento de novos juízes e, como regra, obstaculizar o acesso a instrumentos e equipamentos mais modernos, a remuneração condigna o aperfeiçoamento dos auxiliares do juiz, especialmente daqueles locados em primeiro grau de jurisdição. Se adicionarmos ao quadro a queda vertiginosa da qualidade de ensino e a profunda crise por que atravessa a sociedade brasileira, já beirando à barbárie, o panorama não é dos mais animadores.

R. Fac. Direito UFRGS, Porto Alegre, 10: 175-179, jul. 1994
O Poder Judiciário resiste como pode, a consegue evitar, em todos os seus niveis (com variações regionais e dependendo do grau de jurisdição) permanente atraso na entrega -da prestação jurisdicional. Trate-se de processo ordinário, de execução ou mesmo cautelar o resultado é um só: o término da atividade não isentará o jurisdicionado, na melhor das hipóteses, de vários anos de tortura e sofrimento (para tanto bastará o contendor renitente esgotar a fantástica gama de recursos oferecidos pelo sistema), tempo suficiente de per se para desterrar qualquer veleidade de efetividade da ustiça.

Todavia, mesmo abstraída a crise e a situação patológica, põe-se de qualquer modo em cheque a questão da efetividade, em razão do tempo normalmente necessário para a emissão do ato sentencial ou material de execução, a pressupor regular ouvida das partes, instrução probatória mais ou menos dilatada, reflexão do juiz, etc. Por mais que se acelere o processo ordinário, executivo ou cautelar, sempre se verificará um déficit pelos meios normais, jamais a satisfação da pretensão poderá ser tempestiva se houver urgência.

2. Essa dura realidade conduziu à hiperatividadé do processo cautelar, diríamo melhor da liminar, o principal, senão único, instrumento do sistema jurídico bra sileiro capaz de dar uma solução rápida e expedita para o conflito, em presença da possibilidade de dano à situação material antes da certeza decorrente da declaração definitiva do direito. A amplitude com que se concebeu, na prática judiciária brasileira 
nesses vinte anos de vigência do Código de 1973, a aplicação do processo cautelar, tem sido objeto de constante meditação por parte da doutrina ${ }^{1}$.

A meu ver, dentro do contexto específico da realidade brasileira, impõe-se realçar com mais força o valor da efetividade. $O$ provimento cautelar, inclusive liminar, deve ser imitido, mesmo à custa de uma satisfação provisória, se a situação perigosa só pode ser evitada ou minimizada com a antecipação dos efeitos da futura sentença de mérito. A tanto, aliás, autoriza o Código de 1973, ao facultar ao juiz determinar as medidas adequadas para a prevenção do dano. Entre as duas concepções opostas que se digladiam nessa matéria, uma exigindo a contraposição dos interesses em conflito, outra privilegiando quem se apresente como provável titular do direito, inclino-me pela segunda, quando, sublinho, outra solução não puder ser encontrada para evitar o prejuízo. Claro está que, tanto quanto possível, o juiz deverá procurar minimizar os danos da contraparte. Nos casos-limites, contudo, embora o possível efeito danoso ao interesse do demandado, não se configura um emprego abusivo da cautela, se efetivamente presentes os pressupostos indispensáveis à sua concessão². Parece-me feliz a esse respeito a aguda observação de um estudioso italiano, Ferruccio Tommaseo, que vale a pena reproduzir: "...o legislador prefere seja evitado um prejuízo irreparável a direito cuja existência apareşa provável, ainda ao preso de provocar um dano irreversivel a um direito que, em sede de concessão da medida cautelar, aparece ao invés improvável: em ou cautelar, aparece ao inves improvável: em ondireito improvável ${ }^{3+1}$.

Nem por assim entender menosprezo, no entanto, as garantias próprias do processo de conhecimento, tanto na forma ordinária quanto na sumária, o qual não consi dero um mal em si mesmo, mas uma conquista da humanidade, principalmente depois de despido das inúteis e inúmeras formalidades do direito comum, assim como a democracia, notadamente depois dos sucessos do leste europeu, demonstrou ter ultrapassado a fronteira meramente deológica, consagrando-se como real valor ser preservado. A esse respeito, assoma-me perigosa a minimização sistemática do procedimento ordinário, pois pode conduzir ao desprezo total do próprio processo de conhecimento. $\mathrm{E}$, queira-se ou não, ainda função processual de conhecimento continua sendo o remédio por excelência para a declaração definitiva dos direitos, com a certeza daí decorrente, também ela um valor não desprezivel.

Acontece apenas que, na situação emergencial, o valor certeza cede passo ao valor segurança, como que aguardando a sua vez. Essa autonomia, porém, é relativa. Certamente, o processo cautelar satisfaz a pretensão à segurança (destinado como está a eliminar ou minimizar o perigo), mas o juízo de probabilidade, notadamente com referência ao fumus boni iuris, predestina-se a ser reexaminado ulteriormente em processo de cognição plena e exauriente ${ }^{4}$.

E a minha convicção, de privilegiar em casos tais o valor segurança, reforçou-se quando me dei conta das peculiaridades do sistema jurídico brasileiro, em muito superior, nessa matéria, ao europeu-continental. Basta testificar o tormento da doutrina italiana, antes da Lei no 353 de novembro de 1990, com a ausência de qualquer recurso contra a concessão das chamadas providências de urgência e as perplexidades quanto à possibilidade de revogá-las, suspendê-las ou modificá-las antes da sentença de mérito ${ }^{5}$.

Entre nós, previu o Código de 1973 a revogabilidade ou modificabilidade "a qualquer tempo" (art. 807, $2^{\underline{\mathbf{a}}}$ parte), seguindo na esteira do estatuto de 1939 (art. 687), e - emprego do recurso de agravo de instrumento (art. 522). Mas, além disso, a nota diferencial mais importante encontra-se no relevantíssimo instituto do mandado de segurança e o seu ágil emprego pelos aplicadores do direito, a alterar totalmente os termos do problema. Com efeito, confere incrível e inesperada manejabilidade ao sis tema a possibilidade de imediata revisão do provimento liminar do juiz por tribunal de segundo grau, também por provimento liminar, podendo, a sua vez, este provimento liminar ser revisto pelo órgão colegiado n próxima sessão ${ }^{6}$, sujeitando-se a decisão dele emanada ao controle dos tribunais superiores, por meio de recurso especial ou extraordinário, acoplando-se-lhe medid cautelar com pedido de liminar?

Dessa forma, os possíveis inconvenientes decorrentes da emissão da ordem liminar, corporificadora da garantia constituciona do acesso à jurisdição, mas em aparente infringência à garantia do contraditório, em muito se minimizam, senão desaparecem. Faculta-se, destarte, um autêntico contraditório imediato, não apenas o diferido mencionado pela doutrina européia, como também e sobretudo pronto controle po pelo menos duas instâncias sucessivas superiores. Essa circunstância, além de se presta à fiscalização externa (friso externa) dos interesses contrapostos, reprime os eventuais abusos, adequando o instrumento à sua finalidade essencial. Por tal razão, penso eu os repertórios brasileiros de jurisprudência, como se revela a acompanhamento mais atento, vêm concedendo cada vez meno espaço à jurisdição cautelar. De certa manei ra, a instantânea e amplíssima oportunidade de reexame da liminar aplanou as questões práticas mais angustiantes.

3. No plano teórico, de qualquer sorte restam ainda por elucidar de modo mais completo algumas questões valiosas, cuja análise exaustiva seria descabida nessa sede.

Talvez a mais relevante indagação dig respeito à própria natureza da providência que, ao prevenir ou eliminar o dano (sem dúvida alguma a nota mais característica da tutela cautelar ${ }^{8}$ ), ao mesmo tempo satisfaz, às vezes de modo irreversível, no plano fáctico, e sobre a qual quero tecer algumas considerações.

Continuo pensando que o conteúdo decisional de uma providência não depende de circunstâncias externas, qual seja a irreversibilidade fáctica que dela possa decorrer. O que interessa é o caráter formal, isto é, a idoneidade para adquirir autoridade de coisa julgada e a conseqüente imutabilidade da concretização realizada pela sentença. Ora, a verdadeira e própria sentença cautelar jamais conterá suficiente dose de declaração, em virtude da peculiar cognição do juiz, a se estender apenas à aparência do direito, pela instante necessidade de prevencão do dano e, ainda assim, em juízo de mera verossimilhança. Não se entenda, porém, que inexista conteúdo declaratório na atividade jurisdicional cautelar. Também aqui o juiz aplica a norma de caráter geral ao caso concreto. O problema é a extensão dessa cognição. Certeza sobre a relação jurídica material litigiosa somente haverá $\mathrm{em}$ processo de conhecimento, acelerado ou não'. Ora, se assim é, por mais que se procure relegar a segunda plano a importância do processo de cognição, não há como equiparar a irreversibilidade fáctica com a imutabilidade operativa da coisa julgada material, ante a consubstancial diversidade funcional e estrutural entre ambas. Não se pode confundir o efeito prático com o efeito jurídico, que é no fundo o que interessa ao direito, todo feito de eficácias jurídicas. Com a satisfação da pretensão à segurança, que não é sexta classe de pretensão, não se satisfaz a pretensão à declaração, nem se diz a última palavra sobre condenação, constituição, mandamento ou execuçãa ${ }^{10}$.

De qualquer modo, é realmente atraente sedutora, de lege ferenda, a importante elaboração doutrinária de Ovídio A. Baptista da Silva e Luiz Guilherme Marinoni, incluindo a antecipação provisória numa nova categoria, denominada sugestivamente utela de urgência, fora da tutela cautelar estritamente considerada. Não posso deixar de constatar, no entanto, a identidade de função e estrutura entre ambas. As duas visam, cỏm efeito, à prevenção do dano, são concedidas mediante cognição sumária, em juízo de probabilidade, sem produzir a respectiva sentença coisa julgada material. É certo que aqui se torna menos visível a dependência em relação à futura sentença de mérito, embora de todo inafastável, por necessariamente provisório o provimento de urgência, sujeito a ser revogado se desfa- 
vorável o resultado do processo definitivo. Diversa se exibe tão-somente a natureza do receio de lesão, que resulta na hipótese da própria demora do procedimento e em razão da valia do interesse a resguardar. No sistema positivo atual, contudo, penso que esse tipo de pretensão emergencial só pode desaguar na vala comum do processo cautelar, em face da ampla autorização contida nos arts. 798 e 799 do CPC.

Não se passa o mesmo, no entanto, com certas medidas a que, equivocadamente, atribui-se caráter cautelar, como a maioria das provisionais dos arts. 888 e 889 do estatuto de 1973. O juiz que regula o direito de visita de um dos progenitores, que decide sobre a guarda dos filhos, oficia em ação principal, com rito sumário, dotada de li$\operatorname{minar}^{11}$, mas sem qualquer restrição de monta ao meios empregados pelas partes na defesa de seus pontos de vista.

4. Por fim, entendo útil, ainda que en passant, pela angústia do tempo, comentar rapidamente algumas sugestões de iure con dendo, especialmente ante a cardinal contri buição da doutrina brasileira nestes dois decênios de vigência do estatuto de 1973.

Para começo de conversa, arranque-se do Código todo preconceito com as medidas nominadas de constrição, a exemplo do arresto e do seqüestro, grilhetados servilmente por abstrusas exigências, em obediência ao modelo do velho Código de Processo Civil de São Paulo e das Ordenações do Reino. Aqui, basta lançar os olhos para o próprio Código de 39 que, superiormente, limitava-se sem qualquer adjetivação a permitir arresto e o seqüestro (art. 676, I e II), ou para a experiência de outros povos, como do Código de Processo Civil português, que se basta, no concernente à primeira medida, com o receio de perda da garantia patrimonial e a dedução de factos que tornam provável a existência do crédito e justificam o receio invocado (art. 403, no 1). Reordene-se, outrossim, o capítulo dos procedimentos cautelares específicos, dele extirpando-se o que não é cautelar.

Acentue-se a sumarização e a possibilida de de liminar na tutela jurisdicional dife- renciada, estabilizando-se o resultado nela alcançado, não só para as autênticas medidas provisionais (muitas delas arroladas no art. 888), como especialmente para os direitos em cujo conteúdo ou função predomine o caráter não-patrimonial, a representar momentos de liberdade - formal ou substancial - ou, ainda, se destinados a atender necessidades primárias.

Dispense-se de processo independente e atuação em separado as autênticas cautelas asseguratórias, pois, na generalidade dos casos, como a praxe brasileira comprova, reduzem-se à liminar e se submetem ao contraditório sucessivo do mandado de segurança. Nas cautelas antecipatórias, ins taure-se, sempre que possível, a necessidade de ouvida relâmpago, até oral, da outra parte, antes de emitida a liminar, devendo o respectivo provimento judicial, pena de nulidade absoluta, ser sempre fundamentado, não ser vindo para esse efeito a fórmula vaga e genérica de estarem atendidos os pressupostos.

Amplie-se o poder do juiz brasileiro para regular temporariamente uma relação jurí dica litigiosa. Por fim, estabeleça-se a possibilidade de antecipaşão liminar da tutela ju risdicional, mesmo quando inexistente receio de lesão, se demonstrado na inicial o direito líquido e certo do demandante e documentalmente comprovados os fatos pertinentes.

De qualquer modo, concluo, os lidadores práticos do direito brasileiro e aqueles que, no silêncio de seu gabinete, dedicaram-se a refletir sobre a tutela cautelar, souberam com inteligência e sagacidade convive com essa rica problemática e, de uma ma neira ou outra, encontrar resposta adequad para as copiosas e complexas dificuldades oferecidas por regulação tão delicada.

\section{Notas}

1 Impōe-se destacar o labor de Galeno Lacerda, Calmon de Passos, Humberto Theodoro Júnior, e especiamente a obra de Ovidio A. Baptista da Silva, o jurista brasileiro que mais se tem dedicado ao tema. Dever ser mencionadas, ainda, excelentes monografias recen-
tes sobre o assunto, especialmente as (pela ordem de edição) de Alcides Alberto Munhoz da Cunha, Luiz Guilherme Marinoni, Sérgio Seiji Shimura, Marcos Vinicius de Abreu Sampaio e Betina Rizzato Lara, oriundas, com exceção da primeira,
duação da PUC de São Paulo.

2 Fugiria ao tema o exame do emprego abusivo da cautela, a exemplo da obtenção de providência não congruente com a decisão definitiva ou excedente dos limites desta.

${ }^{3}$ Ferruccio Tommaseo, I Pronvedimenti d'Urgenza (struttura e limiti della tutela anticipatoria), Padova, Cedam, 1983, pág. 155.

${ }^{4}$ Não me parece convincente a defesa da autonomia plena da tutela cautelar realizada por Ugo Rocco, Tra plena da tutela cautelar realizada por Ugo Rocco, TraTorino, Uttet, $1966, \mathrm{n}^{\circ} 12$, págs. $58-63$, esp. pág. 60 , ao
argumento de que nem sempre o provimento definitivo será favorávcl e, nesta hipótese, em sendo contrário vo será favorávcl e, nesta hipótese, em sendo contrário falar de instrumentalidade, restando apenas como único e solitário provimento emitido o provimento-meio. $\mathrm{Na}$ realidade, também ai ressai a dependência: exatamente pelo fracasso ocorrido na demanda principal, o provimento-meio não sobrevive, e há de ser revogado. O meio-fim, a instrumentalidade, tem duas mãos, como sempre ocorre com o fenômeno processual, pela incerteza consubstancial ao direito litigioso.

5 Ver por todos, a respeito do ponto, Crisanto Mandrioli, Corso di Diritto Processuale Civile, III, $6^{2}$ ed., Torino, Giapichelli, 1987, págs. 301-303.

${ }^{6} \mathrm{~A}$ regra de que o agravo regimental deve ser julgado na próxima sessão do órgão colegiado encontra-se e quase todos, senão todos, Regimentos internos das cortes brasileiras. 7 Tanto o STF quanto o STJ têm admitido a atribuição
de efeito suspensivo ao recurso extraordinário ou especial, por meio de medida cautelar, se reunidos os requisitos de toda tutela cautelar $(v \cdot g .$, STF, RTJ, 13/215, RT 613/258, RTJ, 110/458; RST], 12/433, $13 / 215,25 / 273)$ e até em relação ao agravo de instruSTJ 3t Terosto da decisáo negatoria de seguimento DJU 16 Turma, Pet. 128-RJ, rel. Min. Dias Trindade, De quando o recurso, embopreciada ainda sua admissibilidade na conl, por náo (STJ-4 Turma Pet 298-2RS, rel. Min Sálvio de Figueiredo, DJU 31.8.92 pá 13.649). Entendimento divero, porém e a meu parecer menos correto, adota OSTF, ao não admitir o emprego da tutela cautelar enquanto não apreciado o recurso pela presidência do tribunal quo (Pet. 150, RTJ, 116/428; Pet. 260, DJU 27.5.88. Pet. 510-4-MG, DJU 27.9.91). A necessidade instance de revenção do dano que caracteriza toda tutela cautear, não se compadece com tal espera, se presentes o Jumus boni iuris $\mathrm{e}$ o periculum in mora.

Já em 1986, havia entrevisto na prevenção do dano, constituir sua própria razão de ser, a nota mais crocesso caca e marca do processo cautelar: "Todo

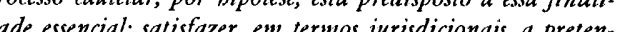
ão à seguransa" (Carlos Alberto Alvaro de Oliveira, Considerasốs sobre a Tutela Cautelar AJURIS, 37 (1986):159-165, esp. pág. 160).

${ }^{9}$ Cf. posicionamento anterior, por mim externado nos Comentários ao Código de Processo Civil (obra escrita em colaboraçâo com Galeno Lacerda), vol. VIII, t. II, $2^{\mathbf{2}}$ .e, Rio, Forense, 1991, $\mathrm{n}^{\circ} 153$, pags. 214215 , com ágs. 147, 151-155.

10 Pontes de Miranda, Tratado das Agóos, tomo VI, São Paulo, RT, 1976, § 27, 1, págs. 329-330.

págs. $366-368,379$. 